\title{
Educating the Public on Hemorrhage Control: Methods and Challenges of a Public Health Initiative
}

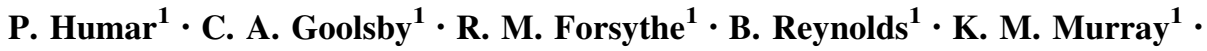 \\ D. Bertoty ${ }^{1}$ A. B. Peitzman ${ }^{1}$ M. D. Neal ${ }^{1}$
}

Published online: 9 April 2020

(C) The Author(s) 2020

\begin{abstract}
Purpose of Review We aim to determine the various models of training and identify educational strategies that would be efficacious in teaching bleeding control to the public.

Recent Findings Recent studies have examined various educational strategies of bleeding control education including lectures, web-based classes, and hands-on training. The effectiveness of these trainings can not only be measured in increases in knowledge, but also in feelings of confidence, preparedness, and willingness to assist in a bleeding emergency. When looking at retention or skills and knowledge, we found that multiple studies showed decreases in ability to stop life-threatening bleeding when retested weeks or months after training. These issues of retention and a lack of education in general lead to a discussion about the possible benefits of having just-in-time (JiT) information during a bleeding emergency.

Summary Based on the recent findings, bleeding control trainings have proven to be a very effective method of providing the general public with necessary skills. Therefore, moving forward, it is crucial to look at retention and the use of JiT information in longitudinal studies.
\end{abstract}

Keywords Bleeding control · Just-in-time information · Tourniquet $\cdot$ Education $\cdot$ Retention $\cdot$ Stop the Bleed ${ }^{\mathrm{TM}}$

This article is part of the Topical collection on Surgical Education.

M. D. Neal

nealm2@upmc.edu

1 University of Pittsburgh Medical Center, F1271.2 PUH, 200

Lothrop Street, Pittsburgh, PA 15213, USA

\section{Introduction}

The increased prevalence of mass casualties in the USA has demanded a need for robust prehospital interventions that can reduce mortality rates from bleeding. In parallel to the increase in intentional mass injury events, life-threatening bleeding can occur from accidents and injuries that occur at home, at work, and in other common scenarios such as motor vehicle collisions. Uncontrolled hemorrhage has risen to be a leading cause of preventable injury death in the USA for individuals less than 45 years of age [1]. Thus, secondary prevention, or the reduction of impact of an injury that has already occurred, has become a major focus in prehospital interventions to prevent death following injury.

Time is of the essence in the setting of life-threatening bleeding, as major vascular injuries can result in death by exsanguination in as little as $3-5 \mathrm{~min}$ [2]. Therefore, it is often not possible to wait until a medical first responder arrives at the scene. As a result, bystanders need to be capable of performing emergency first aid measures. After the mass shooting at Sandy Hook Elementary School, the Hartford Consensus was developed by a broad coalition of more than 70 stakeholder organizations, including the American College of Surgeons, US Department of Defense, and many others to increase the number of trained immediate responders for bleeding control and to promote the message that "everyone can save a life [3]." From this initiative came the Stop the Bleed ${ }^{\mathrm{TM}}$ (STB) campaign which aimed to equip potential bystanders with the knowledge and skills to perform life-saving bleeding control until emergency personnel arrive, concomitant with making bleeding control kits readily available in public spaces. 
A major component of this campaign is the Stop the Bleed $^{\mathrm{TM}}$ training course that aims to teach techniques such as applying pressure, wound packing, and tourniquet application. As this initiative grows, with more than one million individuals trained at the time of this writing, a critical need exists to define best practices and strategies to educate the lay public in bleeding control. As the elements most important to STB training are relatively robust and well-defined, the major questions focus on determining the most effective methods of training the general public. Therefore, this narrative review will specifically focus on the efficacy of various educational strategies for bleeding control training and their effects on bystander attitudes with regard to confidence, preparedness, and willingness to assist in a bleeding emergency. While providing the education is the first step, ability to maintain those skills is crucial and therefore retention of skills and knowledge through the use of re-trainings and just-in-time information will be discussed.

\section{STB Education and Methods of Delivery}

The American College of Surgeons Stop the Bleed ${ }^{\mathrm{TM}}$ course, formerly called Bleeding Control (B-Con), is a widely accepted and effective form of bleeding control training with basic hands-on work in wound packing and tourniquet application [4]. A large focus of this training has been to educate the greatest number of people, effectively increasing the likelihood that in a given situation a bystander will be able to perform bleeding control measures if necessary. Along with considering the number of people trained, it is important to look at who is being trained, with the possibility of tailoring or personalizing methods for specific groups or individuals. This concept is discussed in detail as a tiered training system described by Goolsby et al. as part of the Stop The Bleed Education Consortium [5]. The authors define three distinct tiers including a layperson, trained layperson, and professional tier. These groups are defined and separated based on their medical knowledge and anticipated likelihood of being faced with a bleeding emergency. For example, a layperson may not have a high likelihood of encountering a bleeding emergency and therefore would be less likely to need rigorous training as compared to a medical professional who may have a high chance of encountering this emergency. It is likely that varying content based on the specific group may allow for more appropriate and tailored education, and this Consortium statement provides recommendations for a common framework for the design of curricula.

In conjunction with developing the content of Stop the Bleed $^{\mathrm{TM}}$ education, the method of providing the education is an important consideration. Goralnick et al. performed a study analyzing various educational formats to assess the efficacy of each method [6]. These four methods include an audio kit (with visual aids), instructional flashcards, the Bleeding Control course (B-Con), and a control group with no training. The training success was measured in correct tourniquet application. Eighty-eight percent of participants in the B-Con training group demonstrated correct application $(n=122)$ [6], significantly higher than the participants correctly applying tourniquets in the control (16\%), instructional flashcards (19.6\%), and audio kit (23\%) groups [6]. These findings yield two important implications; the value of having in-person training and the efficacy of hands-on practice of instructional material.

The B-Con training, having both an in-person and a hands-on component, has been repeatedly shown to have a high success rate in teaching Stop the Bleed ${ }^{\mathrm{TM}}$ education. In a study analyzing the efficacy of lecture alone vs. lecture and a B-Con training, participants who received hands-on training (experimental group) were significantly more successful in wound packing and tourniquet application than the participants who received no training (control group) [7]. This study demonstrates that while disseminating information about proper bleeding control measures is important, the hands-on practice component helped with skill performance in this study population.

A vast majority of bleeding control studies have participants complete some form of training before assessing skills. McCarty et al. conducted a self-reported study and indicating some prior form of first aid or bleeding control training increased the likelihood of successful completion of tasks in a bleeding control curriculum [9]. Those who reported first aid (FA) training had a 2.12-higher odds (95\% CI 1.07-4.18) of correct tourniquet application and those with first aid and hemorrhage control training had a 3.50-higher odds (95\% CI 1.59-7.72) of correct application than participants with no training whatsoever [9]. This points to an important concept that education in basic bleeding control is an important step towards equipping bystanders with technical skills that could help in an emergency.

An important consideration in Stop the Bleed ${ }^{\mathrm{TM}}$ training is determining how to most effectively and efficiently train the greatest number of people. One method proposed for this is a train-the-trainer model, which aims to create force multipliers, increasing the number of opportunities to train civilians. This model was designed and implemented in the Western Pennsylvania region as part of the Western PA Stop the Bleed ${ }^{\mathrm{TM}}$ initiative [10]. The strategy was to start by engaging emergency medical services (EMS) that could therefore serve at points of community outreach, especially in communities geographically removed from a major trauma center. The goal was then to work with the local EMS agencies to certify all of their members as trainers 
(train-the-trainer model) to reach the greatest number of individuals in the lay public. The Western PA Stop the Bleed $^{\mathrm{TM}}$ initiative embarked upon the ambitious goal of placing a bleeding control kit in every public school and a tourniquet on the belt of every law enforcement officer in the region. This program spanned over 70 counties in four states, demanding a substantial number of trainers to reach the population. This raises questions as to how to expand the pool of effective trainers. One population of individuals currently being targeted as STB trainers are medical students. In one study addressing this, approximately 400 medical students from two schools were enrolled in the STB course [11]. After the training, $72.4 \%$ of medical students achieved perfect scores on their skill proficiency assessments and of the 48 medical students serving as instructors, all were able to effectively educate participants of an STB course [11]. Training medical students to then train potential bystanders has therefore been recognized as a resource to increase the ability to train people in large numbers. This adds to the growing list of professionals who can be certified as Stop the Bleed ${ }^{\mathrm{TM}}$ instructors [12].

\section{Improvement of Confidence, Preparedness, and Willingness to Assist}

In emergency situations it is important that bystanders feel confident in their abilities and as a result are both prepared and willing to perform necessary life-saving measures. For this reason, several groups have examined how the attainment of knowledge and skills affect the attitudes of bystanders to provide help. Latuska et al. conducted a study to look at these concepts, specifically using a population of school nurses [13]. After completion of a 1-h STB training, increases in knowledge, hands-on skills (wound packing and tourniquet application), and identification of cases of life-threatening bleeding were significantly improved. Prior to the training, most nurses felt relatively neutral about their ability to respond to a life-threatening bleeding emergency, but following the training almost all agreed or strongly agreed that they were confident in their ability to respond to a life-threatening bleeding emergency [13]. This indicates that a basic STB training not only enhances knowledge and skills as previously discussed, but also could be used to improve more intrinsic factors such as self-confidence.

Increases in self-confidence have been thought to correlate with increases in willingness to help during a bleeding emergency, both of which could be improved by obtaining the necessary knowledge and skills. In their study, Lei et al. initially gave participants a survey and found that only $51 \%$ would be likely to assist in scenarios with severe bleeding, many expressing concerns about risks of self-harm or further injuring the victim because of a lack of knowledge and skills [14]. After the training, the percent of individuals indicating they would be willing to help increased to $92 \%$. Additionally, before STB training, as indicated by a survey, $80 \%$ of school nurses, $19 \%$ of medical students, and $48 \%$ of community members felt prepared to help in bleeding emergencies [14]. After the training, these numbers increased to $100 \%$ of school nurses, $98 \%$ of medical students, and $99 \%$ of community members feeling prepared to assist in these emergencies. Similar results were also noted by the McCarty et al. study discussed earlier where participants with prior first aid and hemorrhage control training were more willing to assist and comfortable performing bleeding control measures than those without prior training [9]. These results point to the fact that while the STB training needs to educate and provide information and skills to participants, it also must be structured so that bystanders understand why their immediate response is crucial and feel prepared to help without fear of further injury. This concept is also well described by Knowles principles of adult learning theory, in which he argues that adults are most interested in learning when the topic has immediate relevance and impacts on their job or personal life [8]. Based on this, bystanders who have a strong understanding of how important their role is in administering life-saving measures will be more prepared and willing to use their learned skills if the situation arises.

In a similar study looking at attitudes, specifically looking at tourniquet application, researchers found that when participants were initially asked if they would use a tourniquet in real life, 64.2\% (140/218) responded "Yes" whereas after training 95.6\% (194/203) of participants responded that they would use a tourniquet in a bleeding emergency [15]. Additionally, when asked about their comfort level with using a tourniquet, there was a statistically significant improvement between pre and posttraining response ( 2.5 versus 4.0 , based on 5-point Likert scale) [15]. Tourniquets are often considered to be less intuitive than skills such as applying pressure and wound packing, but nonetheless are crucial to stop bleeding, which is why comfort and willingness specifically with tourniquet application needs to be addressed during STB training.

\section{Retention of Education}

While STB training has been known to improve factors such as knowledge, skills, confidence, willingness, and preparedness in a bleeding emergency, a majority of this information comes from testing immediately after the training takes places. As discussed previously, Ross et al. demonstrated clear increases in bleeding control skills after 
STB training; however, they also discussed concerns regarding retention of skills and education [15]. As time passes, individuals are mostly likely not practicing the skills learned in training, and therefore are likely to forget their training to some degree. This brings into question how well the skills are retained and more importantly if the individuals are still prepared to help in a bleeding emergency as they proved to be immediately after training.

This concern is addressed by Goralnick et al. in a laypersons study showing that of the 303 participants who were assessed 3 to 9 months after undergoing B-Con training, only $165(54.5 \%)$ could correctly apply a tourniquet [6]. This is significantly lower than the $88 \%$ of participants who correctly applied a tourniquet immediately after the B-Con training. In another study looking at retention in community members, Weinman et al. selected a random sample of 46 participants [16]. They found that after an initial training all were able to apply a tourniquet and perform bleeding control measures. When the participants were tested 6 months later, they found that these numbers had decreased to $74 \%$ of people who were able to stop or reduce bleeding to non-threatening level with only $69 \%$ being able to apply a tourniquet correctly [16]. This study highlights the issue of tourniquet application being the common rate-limiting step in retention. While the 6 month decrease in ability to stop life-threatening bleeding was found to be about $26 \%$, upon closer analysis the primary barrier appeared to be application of tourniquets. This is consistent with the findings of Goralnick et al. [6] who found approximately a $50 \%$ decrease in ability to correctly apply a tourniquet months after training. These ideas of retention were also a common finding in studies looking at the general public receiving CPR and first aid training. In a study by Mahoney et al. looking at retention in airline cabin crew members who had successfully completed CPR training. After 12 months, of the 35 subjects, 18 performed chest compressions at the incorrect site and only 20 placed the AED pads correctly [17]. These studies reiterate the fact that retention of learned skills decreases with time, an issue that needs to be addressed to best prepare bystanders to help in a bleeding emergency.

Not only has there been a known deterioration in skills and knowledge in the time after the training, but there also seems to be a significant disconnect between thoughts about the importance of bleeding control and the practices that follow training. In the Dhilon et al. study, participants attended a B-Con class and completed two surveys, one immediately after the training and another one a month after the training [18]. Of the people who responded, $16.4 \%$ of them reported actually purchasing a tourniquet which significantly differs from the $74.7 \%$ indicating they would purchase a tourniquet after completing the class [18]. Additionally, $50.8 \%$ of people indicated purchasing packing materials which are again significantly less than the $76.2 \%$ who reported they would do so at the time of training. Further research indicated that time and money were the most common reasons for not purchasing [18]. This points to the issue that individuals recognize the importance of bleeding control while at the training session, but not strong enough to carry those practices and thoughts with them weeks and months after undergoing the training. These findings, along with the known decreases in retention of skills, has propelled researchers to ask questions about the value of taking refresher classes or providing instructional just-in-time information inside bleeding control kits. This illustrates, perhaps, the greatest unmet challenge of the Stop the Bleed ${ }^{\mathrm{TM}}$ program, and the definition of appropriate time for re-certification, if at all, is an active area of investigation.

\section{Just-in-Time Information}

One of the Stop the Bleed ${ }^{\mathrm{TM}}$ (STB) campaign's five objectives is that all bleeding control kits will provide justin-time (JiT) audio and visual training for users [19]. STB creators were concerned about known problems teaching other life-saving resuscitative skills, such as CPR, to the public. They hoped that JiT instruction would help improve bleeding control at the point of need, while increasing scalability and reach of the campaign. JiT education describes learning that takes place at the time the knowledge or skill is needed, rather than learning it in advance and retaining the knowledge until needed. It is used in other high-stakes settings faced by the public, such as emergency exit row training on an aircraft or fire extinguisher instructions. JiT can be stand-alone education or used to augment or refresh previously acquired knowledge or skills. JiT education is also supported by adult educational theory. Knowles argues that adults learn particularly well when they know why they are learning something, and can immediately apply the new knowledge [8]. Both of these conditions lend themselves well to JiT education when faced with a life-threatening condition. CPR training, which has historically been taught in an instructor-led, classroom-based model, has relied on learner knowledge retention as a core feature of its educational design. Learners take a class, and then must remember what they learned in class indefinitely until needed in the future. Trainees with occupational needs, such as healthcare workers, will usually re-certify, but the lay public may not necessarily ever take a subsequent course. There is evidence that CPR skill performance declines rapidly after training, and that learners may be only $30 \%$ successful performing skills in as little as two months following training [20]. Alternative educational modalities, such as 
kiosk and video-based learning for CPR, have shown promise when compared with classroom-based learning [20-23].

Armed with the STB campaign's mandate and background in CPR challenges, investigators began assessing the feasibility of JiT education for hemorrhage control. There is a series of studies by Goolsby et al. that tested JiT education in 577 laypeople [24-26]. They consistently found that untrained people successfully apply tourniquets about $20 \%$ of the time, while those with a JiT education card, specifically designed for the public, apply tourniquets correctly about half the time [24-26]. This increases to approximately $75 \%$ success with brief web-based education [26]. While these numbers are not optimal, they compare favorably to the CPR numbers above, and are similar to the approximately half of laypeople able to apply a tourniquet successfully a few months after in-person training [6]. These findings, combined with STB campaign objectives, experience with CPR, and a desire to reach the entire public, should encourage STB educators to adopt an "all of the above" approach. This includes continuing to develop and test varied, scalable, educational options to reach learners with different needs.

\section{Discussion}

When the Stop the Bleed ${ }^{\mathrm{TM}}$ educational campaign was launched, the most pressing issue to address was determining the most effective method of providing training. While lecture in the format of audio and visual instruction are important, a hands-on training approach has been widely used to teach the bleeding control course. However, it is important to note additional bleeding control programs that exist, including the Until Help Arrives course by the American College of Emergency Physicians (ACEP) which provides both a web-based and hands-on training component. This is in contrast to the bleeding control programs designed by the Federal Emergency Management Agency (FEMA) and American Red Cross which focus on certification through online courses only. While there is little significant data comparing these courses with the widely used STB course, there have been discussions about the widespread availability of online training as compared to the ability of in-person classes to provide hands-on training and live practice. A more in-depth understanding of the strengths and weaknesses of each of these will be important areas of research.

With these teaching models in place, a major emphasis is now to determine how to train the greatest number of people without compromising the quality and effectiveness of the training. With the train-the-trainer model discussed, a concern lies in the variability among trainers. Minute details regarding wound packing and tourniquet application are very important and can be miscommunicated or entirely missed if the trainer is not thorough. While medical students and other health care professionals have been identified as a pool to increase the number of trainers, the challenge will be to continue finding individuals or groups of people who are qualified and effective STB teachers to meet the demands of an ambitious goal to make STB training as common as CPR.

Given the increasing numbers of individuals getting STB training, looking at issues with retention of skills and information has become an important question. This ties back to the fact that while participants can effectively demonstrate bleeding control skills post-training, those skills may not be as accurate or clear weeks, months, and years after training. The issue then lies in the best way to address retention. Based on the data reviewed here, it appears that the two most logical avenues are to have participants receive re-certification trainings and/or to include just-in-time information sheets alongside bleeding control kits.

Re-certification courses would function to help participants practice their skills and allow trainers to address any gaps or misinformation in knowledge and skills that could arise with time. This is especially important for tourniquet application, as those skills are shown to decay the fastest. If re-certifications were to be implemented, guidelines would need to be developed in terms of how often these would be mandated. It would be valuable to make distinctions for recertification requirements based on how often emergency procedures are practiced or how likely individuals are to be faced with a bleeding emergency. For example, some medical professionals may require less frequent re-certifications due to the nature of their everyday work while school faculty may warrant more frequent re-certifications due to the prevalence of bleeding emergencies in school settings. Cost of re-certification is also a major contributing factor in an initiative largely supported by volunteerism and philanthropy.

Given the limited number of STB trainers and resources combined with the practical reality of teaching 300 million people bleeding control skills, regular re-training seems unfeasible. Thus, just-in-time training, as well as innovative practices such as web application-based formats for response to life-threatening bleeding, is critical area of focus for future research. While these would not replace the in-person, hands-on trainings, they would serve as a supplement to guide people through skills that could be forgotten with time. Moving forward, it seems critical to learn more about the impacts of JiT information through longitudinal studies looking at retention. This would allow us to look at previously trained individuals and specifically see how the JiT information can be useful for those who 
already have some knowledge of bleeding control procedures. In doing this, we can better address issues of retention and determine if JiT information would eliminate the need for re-certification trainings.

\section{Conclusion}

In summary, the incredibly enthusiastic response of the public to Stop the Bleed ${ }^{\mathrm{TM}}$ training has led to a rapid pace of growth. While exciting and encouraging, this leaves incumbent upon the leadership of this initiative the task of defining best practices in education for this topic. Overall, research has demonstrated the public's ability to learn lifesaving bleeding control knowledge and skills; however, more information is urgently needed to sustain and maintain the rapid growth of this critically important public health initiative.

\section{Disclaimer}

This article is the opinion of the authors' and does not represent the official policy or position of the Uniformed Services University, Defense Department, or US Government.

\section{Compliance with Ethical Standards}

Conflict of interest The authors declare that they have no conflicts of interest.

Human and Animal Rights and Informed Consent This article does not contain any studies with human or animal subjects performed by any of the authors.

Open Access This article is licensed under a Creative Commons Attribution 4.0 International License, which permits use, sharing, adaptation, distribution and reproduction in any medium or format, as long as you give appropriate credit to the original author(s) and the source, provide a link to the Creative Commons licence, and indicate if changes were made. The images or other third party material in this article are included in the article's Creative Commons licence, unless indicated otherwise in a credit line to the material. If material is not included in the article's Creative Commons licence and your intended use is not permitted by statutory regulation or exceeds the permitted use, you will need to obtain permission directly from the copyright holder. To view a copy of this licence, visit http://creativecommons. org/licenses/by/4.0/.

\section{References}

1. Ezeibe C, McCarty JC, Chaudhary MA, De Jager E, HerreraEscobar J, Andriotti T, Jarman MP, Ortega G, Goralnick E. Haemorrhage control in the prehospital setting: a scoping review protocol. BMJ Open. 2019;9:e029051.
2. Jones AR, Brown MR, Esslinger A, Strickland VS, Kerby JD. Evaluation of "Stop the Bleed" training among K-12 faculty and staff in Alabama. Public Health Nurs. 2019;36:660-6.

3. Jacobs LM, et al. The Hartford Consensus III: implementation of bleeding control: if you see something do something. Bull Am Coll Surg. 2015;100(1 Suppl):40-6.

4. Zhao KL, et al. Learners' perspectives on Stop the Bleed: a course to improve survival during mass casualty events. Trauma Surg Acute Care Open. 2019;4(1):e000331.

5. Goolsby C, Jacobs L, Hunt RC, Goralnick E, Singletary EM, Levy MJ, Goodloe JM, Epstein JL, Strauss-Riggs K, Seitz SR, et al. Stop the Bleed Education Consortium: education program content and delivery recommendations. J Trauma Acute Care Surg. 2018;84:205-10.

6. Goralnick E, Chaudhary MA, McCarty JC, Caterson EJ, Goldberg SA, Herrera-Escobar JP, McDonald M, Lipsitz S, Haider AH. Effectiveness of instructional interventions for hemorrhage control readiness for laypersons in the Public Access and Tourniquet Training Study (PATTS): a randomized clinical trial. JAMA Surg. 2018;153:791-9.

7. -Zwislewski A, Nanassy AD, Meyer LK, Scantling D, Jankowski MA, Blinstrub G, Grewal H (2019) Practice makes perfect: the impact of Stop the Bleed training on hemorrhage control knowledge, wound packing, and tourniquet application in the workplace. Injury 50:864-868. This study, like many others, shows the importance of a hands-on training component to STB education by specifically looking at the efficacy of lecture alone vs. lecture and hands-on training.

8. Knowles MS, Holton EF, Swanson RA. The adult learner: the definitive classic in adult education and human resource development. 8th ed. New York: Routledge; 2015.

9. McCarty JC, Caterson EJ, Chaudhary MA, Herrera-Escobar JP, Hashmi ZG, Goldberg SA, Goolsby C, Lipsitz S, Haider AH, Goralnick E. Can they stop the bleed? Evaluation of tourniquet application by individuals with varying levels of prior self-reported training. Injury. 2019;50:10-5.

10. Neal MD, Reynolds BR, Bertoty D, Murray KJ, Peitzman AB, Forsythe RM (2018) Design and implementation of the Western Pennsylvania regional Stop the Bleed initiative. J Trauma Acute Care Surg 85:684-690. This study highlights the train-the-trainer model and states its role in determining how to provide bleeding control skills to the greatest number of people.

11. Schroll R, Smith A, Zeoli T, Hoof M, Greiffenstein P, Moore M, McGrew P, Duchesne J, Avegno J. Efficacy of medical students as stop the bleed participants and instructors. J Surg Educ. 2019;76:899-1162.

12. American College of Surgeons. Stop the Bleed instructor application. https://cms.bleedingcontrol.org/applicant/create

13. Latuska KM, Graf RL, Zwislewski A, Meyer LK, Nanassy AD. Stop the Bleed training improves knowledge, skills, and confidence among school nurses. J Contin Educ Nurs. 2019;50:501-7.

14. •Lei R, Swartz MD, Harvin JA, Cotton BA, Holcomb JB, Wade CE, Adams SD (2019) Stop the Bleed training empowers learners to act to prevent unnecessary hemorrhagic death. Am J Surg 217:368-372. This study shows concrete data regarding increases in both feelings of preparedness and willingness to assist following completion of a STB training course.

15. Ross EM, Redman TT, Mapp JG, Brown DJ, Tanaka K, Cooley CW, Kharod CU, Wampler DA. Stop the Bleed: the effect of hemorrhage control education on Laypersons' Willingness to respond during a traumatic medical emergency. Prehosp Disaster Med. 2018;33:127-32.

16. •Weinman S (2019) Retention of tourniquet application skills following participation in a bleeding control course. J Emerg Nurs. This study serves not only shows the issues with retention of 
skills 6 months after STB training but also discusses tourniquet application as a possible rate limiting step in bleeding control.

17. Mahony PH, et al. Retention of knowledge and skills in first aid and resuscitation by airline cabin crew. Resuscitation. 2008;76(3):413-8.

18. Dhillon NK, Dodd BA, Hotz H, Patel KA, Linaval NT, Margulies DR, Ley EJ, Barmparas G. What happens after a stop the bleed class? The contrast between theory and practice. J Surg Educ. 2019;76:446-52.

19. JEMS Staff. What the White House's stop the bleed campaign means for EMS. https://www.jems.com/articles/print/volume-41/ issue-40/special-focus-gearing-up-for-active-shooter-tacticalhigh-threat-incidents/what-the-white-house-s-stop-the-bleedcampaign-means-for-ems.html. Accessed 5 Apr 2016.

20. Einspruch EL, Lynch B, Aufderheide TP, Nichol G, Becker L. Retention of CPR skills learned in a traditional AHA Heartsaver course versus 30-min video self-training: a controlled randomized study. Resuscitation. 2007;74(3):476-86.

21. Chang MP, Gent LM, Sweet M, Potts J, Ahtone J, Idris AH. A novel educational outreach approach to teach hands-only cardiopulmonary resuscitation to the public. Resuscitation. 2017;116:22-6.

22. Benoit JL, Vogele J, Hart KW, Lindsell CJ, McMullan JT. Passive ultra-brief video training improves performance of compression-only cardiopulmonary resuscitation. Resuscitation. 2017;115:116-9.

23. Panchal AR, Meziab O, Stolz U, et al. The impact of ultra-brief chest compression-only CPR video training on responsiveness, compression rate, and hands-off time interval among bystanders in a shopping mall. Resuscitation. 2014;85(9):1287-90.

24. Goolsby C, Branting A, Chen E, Mack E, Olsen C. Just-in-time to save lives: a pilot study of layperson tourniquet application. Acad Emerg Med. 2015;22(9):1113-7.

25. Goolsby C, Chen E, Branting A, et al. Analysis of layperson tourniquet application using a novel color-coded device. Disaster Med Public Health Preparedness. 2016;10(2):274-80.

26. •Goolsby C, Strauss-Riggs K, Klimczak V, et al (2018) Brief, web-based education improves lay rescuer application of a tourniquet to control life-threatening bleeding. AEM Educ Train 2(2):141-161. This study looks at JiT information as a way to combat retention issues by specifically looking at it value in serving as a teaching source in conjunction with a web-based class.

Publisher's Note Springer Nature remains neutral with regard to jurisdictional claims in published maps and institutional affiliations. 